\title{
Climate, Landscape and the Environments of Visceral Leishmaniasis Transmission in India, Using Remote Sensing and GIS
}

Palaniyandi $\mathbf{M}^{1 *}$, Anand $\mathrm{PH}^{2}$ and Maniyosai $\mathbf{R}^{2}$

${ }^{1}$ Remote Sensing and GIS laboratory, Vector Control Research Centre, (ICMR), Indira Nagar, Pondicherry-605006, India

${ }^{2}$ Geospatial Digital Mapping laboratory, PG and Research Department of Geography, Government Arts College (Autonomous), Kumbakonam, Tamil Nadu, India

\begin{abstract}
Background: The Indian sub-continent is prone to the occurrences of chronic Visceral Leishmaniasis (VL) or Kalaazar, and geographical distribution of disease is endemic in the states of Bihar, West Bengal, Uttar Pradesh, Jharkhand, Delhi, Gujarat, Madhya Pradesh and Kerala in India. The world distribution of Kala-azar chronic cases occurring in the countries, such as, Brazil, India, Nepal, Bangladesh and Sudan, and the $90 \%$ of the disease has been mainly affected the children of below 9-15 years old, and it has been causing $50 \%$ of the cases turn to become deaths incidents occurred annually in India. Visceral Leishmaniasis (VL), a chronic disease caused by Leishmania donovani parasites is transmitted by female phlebotomine sandfly, Phlebotomous argentipes. It has been claimed heavy death toll of human lives in South-east Asia, especially in India.
\end{abstract}

Materials and methods: Visceral Leishmaniasis database was developed in the Dbase format using the MS Excel software and later on imported to the Maplnfo Professional 4.5 GIS software platform and Arc View 3.2 Spatial analyst software platform for mapping the Visceral Leishmaniasis epidemics from 1950 to 2012. The VL epidemic data was overlaid on the IRS WiFS data of indigenous satellite remote sensing, and the NDVI value was used for spatial auto correlation analysis.

Results and discussion: The Visceral Leishmaniasis vector (sandfly) abundance has been found in the period of months between June and September, and the best fit for the distribution of $P$. martini is the dry season composite NDVI $0.07-0.38$ and LST $22-33^{\circ} \mathrm{C}$ with a predictive value of $93.8 \%$, and the best fit for $P$. orientalis is the wet season composite NDVI -0.01 to 0.34 and Land Surface Temperature (LST) $23^{\circ} \mathrm{C}-34^{\circ} \mathrm{C}$ The predictive climate model shows the best fit with the average altitude $(12 \mathrm{~m}-1900 \mathrm{~m})$, average annual mean temperature $\left(15^{\circ} \mathrm{C}-30^{\circ} \mathrm{C}\right)$, annual rainfall $(274 \mathrm{~mm}$ $-1212 \mathrm{~mm})$, average annual potential evapotranspirations $(1264-1938 \mathrm{~mm})$ and readily available soil moisture $(62-113$ $\mathrm{mm})$ for $P$. martini and average altitude $(200 \mathrm{~m}-2200 \mathrm{~m})$, annual rainfall $(180 \mathrm{~mm}-1050 \mathrm{~mm})$, annual mean temperature $\left(16^{\circ} \mathrm{C}-36^{\circ} \mathrm{C}\right)$ and readily available soil moisture $(67-108 \mathrm{~mm})$, alluvial and black cotton soils dark coloured alkaline in nature $(\mathrm{pH} 7.2-8.5)$, calcareous with chief inorganic constituents of silicon, iron and aluminium most suitable for both P. orietalis and Phlebotomus papatasi. The stratification of Kala-azar transmission risk areas was classified, based on the climate variables, and the spatial relationship between the climate variables and VL statistically significance with $93.8 \%$, accuracy.

Conclusion: The longevity and survival of vector populations of Kala-azar has been geographically controlled by the climate (temperature, relative humidity, saturation deficiency, and rainfall), soil types and soil moisture. These climate variables and soil types have been progressively affect the vegetation growth and density, and then the conditions on the surrounding environment. Geographical information systems (GIS) and remote sensing were used to stratify a region into different areas of transmission risk, thereby providing a guideline to mapping the areas under the risk of visceral leishmaniasis transmission in India.

Keywords: GIS; Remote sensing; NDVI; Visceral leishmaniasis; Kala azar; Sandfly; Phlebotomine sandfly; Phlebotomous argentipes; Climate variables

\section{Introduction}

The Indian sub-continent is prone to the occurrences of chronic Visceral Leishmaniasis (VL) or Kala-azar, and geographical distribution of disease is endemic in the states of Bihar, West Bengal, Uttar Pradesh, Jharkhand, Delhi, Gujarat, Madhya Pradesh and Kerala in India. The world distribution of Kala-azar chronic cases occurring in the countries, such as, Brazil, India, Nepal, Bangladesh and Sudan, and the $90 \%$ of the disease has been mainly affected the children of below 9-15 years old, and it has been causing $50 \%$ of the cases turn to become deaths incidents occurred annually in India [1]. The northeastern regions of India, southern region of Nepal and eastern and central division of Bangladesh in South-East Asia are prone to endemic regions of Visceral Leishmaniasis transmission. The reports of Kalaazar cases occurring in Bihar state in India, which is $40 \%$ to $50 \%$, of the world cases and is severely affected states, and account to $90 \%$ of the total recorded cases in India.
Visceral Leishmaniasis (VL) or Kala-azar (KA), a chronic disease caused by Leishmania donovani parasites is transmitted by female phlebotomine sandfly, Phlebotomous argentipes [2]. It has been claimed heavy death toll of human lives in South-east Asia [3], especially in India, where it is one of the major causes of morbidity and mortality, creating a significant impediment to human development.

*Corresponding author: Palaniyandi M, Remote Sensing and GIS laboratory, Vector Control Research Centre, (ICMR), Indira Nagar, Pondicherry-605006, India, Tel: 91-143-2274316; E-mail: smp.geog@gmail.com

Received June 04, 2014; Accepted June 06, 2014; Published June 12, 2014

Citation: Palaniyandi M, Anand PH, Maniyosai R (2014) Climate, Landscape and the Environments of Visceral Leishmaniasis Transmission in India, Using Remote Sensing and GIS. J Geophys Remote Sensing 3: 122. doi:10.4172/2169 0049.1000122

Copyright: (c) 2014 Palaniyandi M, et al. This is an open-access article distributed under the terms of the Creative Commons Attribution License, which permits unrestricted use, distribution, and reproduction in any medium, provided the original author and source are credited. 
The area of distribution of Visceral Leishmaniasis (VL) extends from the Asian shores of the Pacific Ocean to the straits of Gibraltar [4]. Moreover, incidence of this disease continues its unabated journey globally [5], exacerbated by failure of affordable vaccine development; complemented with incomplete dose of the drug consumed by the victims owing to lack of awareness of the latter [6,7]. Declining per capita expenditure on health $[1,8,9]$, poverty [10], illiteracy etc. add to the menace. Historically, in India Kala-azar broke out in epidemic form at intervals of 15-20 years, each episode lasting three to four years (Davey and Lightbody [11]). The epidemiologist and other scientists who have been used the thematic spatial mapping techniques for understanding the occurrences of Visceral Leishmaniasis, and then predictive modeling of climate, landscape, and the environment of Visceral Leishmaniasis transmission [12-14], including mapping, and risk assessment, using remote sensing and GIS, concluded that climate, vegetation, and soil types determinants have been spatially controlled by the geographic distributions $[15,16]$.

The vegetation indices have the distinctiveness of high sensitivity to soil background, which alters the local environment to vector abundance (sand fly, the vector of Visceral Leishmaniasis/Kala-azar) and disease transmission [17]. The longevity and survival of vector populations of Kala-azar has been geographically controlled by the climate (temperature, relative humidity, saturation deficiency, and rainfall), soil types and soil moisture. These climate and soil types have been progressively affect the vegetation growth and density, and then the conditions on the surrounding environment. Geographical information systems (GIS) and remote sensing were used to identify important geographical risk factors and stratify a region into different areas of transmission risk, thereby providing a guideline to mapping the areas under the risk of visceral leishmaniasis transmission in India.

\section{Rationale of the Study}

Visceral Leishmaniasis (VL) or Kala-azar is a chronic and deadly disease caused by Leishmania donovani parasites, is transmitted by female phlebotomize sandfly, Phlebotomous argentipes. It has been serious threat to the public, is endemic in Brazil, Bangladesh, Nepal, Sudan and India. In India, it is endemic in the states of Bihar, Uttar Pradesh and West Bengal, and it has been reported that Bihar state alone account to 40 to $50 \%$ of the total case in India. India alone contributes $90 \%$ of the total cases of world reports, and hence, it is a very serious challenging problem to India. The vector abundance and the disease transmission are directly or indirectly controlled by the climate, landscape environment variables and which are fueling to the occurrences of epidemic cases. Therefore, the present study is made for choosing hybrid remote sensing and GIS for mapping of transmission risk of Visceral Leishmaniasis in India.

\section{Objectives of the Study}

$\checkmark$ To mapping the intensity of Visceral Leishmaniasis distribution in India (2012), using GIS software.

$\checkmark$ To study the climate, landscape, and the environment of Visceral Leishmaniasis epidemic transmission in India, using remote sensing and GIS.

\section{Materials and Methods}

The occurrences of Visceral Leishmaniasis epidemics data was collected from the various available sources of published records including the National Vector Borne Disease Control Programme (NVBDCP), New Delhi. The database was developed in the Dbase format using the MS Excel software and later on imported to the MapInfo Professional 4.5 GIS software platform and Arc View 3.2 Spatial analyst software platform for mapping the Visceral Leishmaniasis epidemics (Table 1, Figures 1 and 2). SPSS 10.0 was used for analyzing the spatial relationship between the climate variables and Visceral Leishmaniasis. The image processing of multispectral indigenous IRS WiFS data along with geo-referenced epidemiological data, integrated in to the geo-statistical analysis for analyzing the spatial agreements between the NDVI and the Visceral Leishmaniasis epidemics cases. The stratification of areas was constructively classified for identifying the VL epidemic transmission zones in India (Figure 3).

\section{Results and Discussion}

\section{Climate, landscape and the environment of Visceral Leishmaniasis transmission}

The geo-climatic aspects related to the occurrence of Visceral Leishmaniasis, sandfly fever and Cutaneous Leishmaniasis are highly determined by the geo-climatic and the variables. The Visceral Leishmaniasis vector (sandfly) abundance has been found in the period of months between June and September; with $P$. argentipes most active profusion when the temperature is range between $27.5^{\circ} \mathrm{C}$ and $31^{\circ} \mathrm{C}$ [18]. The impact of temperature on sandfly populations is rapid and the distribution vegetation condition and synoptic temperature to an overall accuracy of more than $80 \%$ [19]. The geographical and seasonal distribution of the major vectors Phlebotomus martini and Phlebotomus orientalis of kala-azar (Visceral Leishmaniasis) is analyzed using geographic information system (GIS), the best fit for the distribution of P. martini is the dry season composite NDVI 0.070.38 and LST $22-33^{\circ} \mathrm{C}$ with a predictive value of $93.8 \%$, and the best fit for $P$. orientalis is the wet season composite NDVI -0.01 to 0.34 and Land Surface Temperature (LST) $23^{\circ} \mathrm{C}-34^{\circ} \mathrm{C}$ with a predictive value of $96.3 \%$. The predictive climate model shows the best fit with the average altitude $(12 \mathrm{~m}-1900 \mathrm{~m})$, average annual mean temperature $\left(15^{\circ} \mathrm{C}-30^{\circ} \mathrm{C}\right)$, annual rainfall $(274 \mathrm{~mm}-1212 \mathrm{~mm})$, average annual potential evapotranspirations $(1264-1938 \mathrm{~mm})$ and readily available soil moisture $(62-113 \mathrm{~mm})$ for P. martini [15], and average altitude $(200 \mathrm{~m}-2200 \mathrm{~m})$, annual rainfall $(\mathrm{I} 80 \mathrm{~mm}-1050 \mathrm{~mm})$, annual mean temperature $\left(16^{\circ} \mathrm{C}-36^{\circ} \mathrm{C}\right)$ and readily available soil moisture (67$108 \mathrm{~mm}$ ), alluvial and black cotton soils dark coloured alkaline in nature ( $\mathrm{pH} 7.2-8.5)$, calcareous with chief inorganic constituents of silicon, iron and aluminium most suitable for both P.orietalis and Phlebotomus papatasi [15]. The stratification of Kala-azar transmission risk areas was classified, based on the climate variables including the temperature difference between areas suitable and unsuitable for sandfly survival and profusion of vector found to be $\pm 4^{\circ} \mathrm{C}$ and hence, the stratification of the areas under risk of disease transmission have been incredibly sensitive and statistically significant.

In India, the specific crop vegetation types have been correlated with Kala-azar transmission. For example, a study by Sudhakar [14] examined that during summer (March-June) and rainy season (JulyOctober) there was increasing trend of irrigation as well as water areas, with edible shrubs and plants, alluvial soil type, dark coloured alkaline in nature ( $\mathrm{pH} 7.2-8.5)$, calcareous with chief inorganic constituents of silicon, iron and aluminium, This nature of soil enhances its capability of retaining water as well as successful growth and abundance of edible shrubs, plants or agricultural crops. However, in non-endemic study sites, red and yellow laterite soils, with non-porous granular particles are not only acidic in nature ( $\mathrm{pH}$ 5.9-6.1) but are also of less water retaining capacity. This does not assist the growth/propagation of 
Citation: Palaniyandi M, Anand PH, Maniyosai R (2014) Climate, Landscape and the Environments of Visceral Leishmaniasis Transmission in India, Using Remote Sensing and GIS. J Geophys Remote Sensing 3: 122. doi:10.4172/2169-0049.1000122

Page 3 of 6

\begin{tabular}{|c|c|c|c|c|c|c|c|c|c|c|c|c|c|c|}
\hline Year & $\begin{array}{l}\text { Cases \& } \\
\text { Deaths }\end{array}$ & Bihar & $\begin{array}{l}\text { West } \\
\text { Bengal }\end{array}$ & $\begin{array}{c}\text { Uttar } \\
\text { Pradesh }\end{array}$ & $\begin{array}{l}\text { Jhar } \\
\text { khand }\end{array}$ & Delhi & Assam & $\begin{array}{l}\text { Uttra } \\
\text { khand }\end{array}$ & Sikkim & Gujarat & $\begin{array}{l}\text { Madhya } \\
\text { Pradesh }\end{array}$ & $\begin{array}{l}\text { Himachal } \\
\text { Pradesh }\end{array}$ & Tamil Nadu & India \\
\hline \multirow[t]{2}{*}{2000} & Cases & 12909 & 1344 & 47 & 469 & 84 & 0 & 0 & 0 & 0 & 0 & - & 0 & 14753 \\
\hline & Deaths & 130 & 11 & 0 & 0 & 9 & 0 & 0 & 0 & 0 & 0 & - & 0 & 150 \\
\hline \multirow[t]{2}{*}{2001} & Cases & 10327 & 1238 & 22 & 589 & 62 & 0 & 0 & 1 & 1 & 0 & - & 1 & 12239 \\
\hline & Deaths & 204 & 4 & 3 & 0 & 2 & 0 & 0 & 0 & 0 & 0 & - & 0 & 213 \\
\hline \multirow[t]{2}{*}{2002} & Cases & 9684 & 1592 & 32 & 758 & 74 & 0 & 0 & 0 & 0 & 0 & - & 0 & 12140 \\
\hline & Deaths & 160 & 5 & 1 & 0 & 2 & 0 & 0 & 0 & 0 & 0 & - & 0 & 168 \\
\hline \multirow[t]{2}{*}{2003} & Cases & 13960 & 1487 & 34 & 2607 & 126 & 0 & 0 & 0 & 0 & 0 & - & 0 & 18214 \\
\hline & Deaths & 187 & 7 & 1 & 5 & 10 & 0 & 0 & 0 & 0 & 0 & - & 0 & 210 \\
\hline \multirow[t]{2}{*}{2004} & Cases & 17324 & 3015 & 34 & 4028 & 78 & 0 & 0 & 0 & 0 & 0 & - & 0 & 24479 \\
\hline & Deaths & 107 & 23 & 2 & 14 & 9 & 0 & 0 & 0 & 0 & 0 & - & 0 & 155 \\
\hline \multirow[t]{2}{*}{2005} & Cases & 23383 & 2706 & 73 & 6578 & 62 & 1 & 0 & 0 & 0 & 0 & - & 0 & 32803 \\
\hline & Deaths & 124 & 15 & 2 & 12 & 4 & 0 & 0 & 0 & 0 & 0 & - & 0 & 157 \\
\hline \multirow[t]{2}{*}{2006} & Cases & 29711 & 1843 & 83 & 7508 & 31 & 0 & 0 & 0 & 2 & 0 & - & 0 & 39178 \\
\hline & Deaths & 162 & 10 & 0 & 11 & 4 & 0 & 0 & 0 & 0 & 0 & - & 0 & 187 \\
\hline \multirow[t]{2}{*}{2007} & Cases & 37819 & 1817 & 69 & 4803 & 19 & 0 & 2 & 0 & 4 & 0 & - & 0 & 44533 \\
\hline & Deaths & 172 & 9 & 1 & 20 & 0 & 0 & 0 & 0 & 1 & 0 & - & 0 & 203 \\
\hline \multirow[t]{2}{*}{2008} & Cases & 28489 & 1256 & 26 & 3690 & 34 & 98 & 0 & 4 & 0 & 1 & 0 & 0 & 33598 \\
\hline & Deaths & 142 & 3 & 0 & 5 & 0 & 0 & 0 & 1 & 0 & 0 & 0 & 0 & 151 \\
\hline \multirow[t]{2}{*}{2009} & Cases & 20519 & 756 & 17 & 2875 & 12 & 26 & 2 & 5 & 0 & 0 & 0 & 0 & 24212 \\
\hline & Deaths & 80 & 0 & 1 & 12 & 0 & 0 & 0 & 0 & 0 & 0 & 0 & 0 & 93 \\
\hline \multirow[t]{2}{*}{2010} & Cases & 23084 & 1482 & 14 & 4305 & 33 & 12 & 0 & 3 & 0 & 0 & 6 & 0 & 29000 \\
\hline & Deaths & 95 & 4 & 0 & 5 & 0 & 0 & 0 & 0 & 0 & 0 & 1 & 0 & 105 \\
\hline \multirow[t]{2}{*}{2011} & Cases & 25222 & 1962 & 11 & 5960 & 19 & 0 & 0 & 7 & 0 & 0 & 1 & 0 & 33187 \\
\hline & Deaths & 76 & 0 & 1 & 3 & 0 & 0 & 0 & 0 & 0 & 0 & 0 & 0 & 80 \\
\hline \multirow[t]{2}{*}{2012} & Cases & 16056 & 995 & 5 & 3535 & 10 & 0 & 7 & 1 & 0 & 0 & 0 & 0 & 20609 \\
\hline & Deaths & 27 & 0 & 0 & 1 & 0 & 0 & 1 & 0 & 0 & 0 & 0 & 0 & 29 \\
\hline
\end{tabular}

Data source: NVBDCP, Ministry of Health \& Family Welfare, Government of India.

Table 1: Kala-Azar Cases and Deaths in India (2000 to 2012).

shrub/soft-stemmed plants. So physical as well as chemical nature or soil supplemented with water retaining capacity can also be considered as an important factor contributing to much more positive sandflygenic conditions in endemic study sites in contrast to non-endemic study sites [1].

While in endemic sites thatched, mud plastered roof tops of households with crack and crevices on it as well as on walls may serve as effective day-resting habitats for these nocturnal feeder species, mainly tiled, dry, non-porous roof tops without any cracks/crevices in endemic foci cannot be a resting habitat for the adult population. Again loose, wet solid with rich organic debris, on house floors in endemic sites not only serve as a very good resting habitat/food source for thriving and probation of immature stages of vector sandfly, but also act as resting habitat of newly emerged adult population. Thereby, to some extent, factors in micro focus like housing pattern/house floors also determines vector abundance/resting place. As vegetation and human settlements support the thriving of adult population by providing food and shelter, the adult densities were correlated with spatial changes in vegetation cover and human settlements. Because of parallel increasing trend of adult population was observed in these seasons thus indicative of the positive correlation.

\section{Remote sensing and GIS for Mapping Visceral Leishmaniasis Transmission}

The land use/land cover thematic map derived from the indigenous satellite remote sensing are available to reference, however, very limited number of reported research studies available relevant to Visceral Leishmaniasis in India. The vegetation indices derived from high resolution satellite data, have an important role in producing baseline map to monitoring spatial and temporal aspects of vector habitats, vector abundance, threshold limit, and the probability of people at risk of Visceral Leishmaniasis transmission. The large amount of VL vector profusion is occurring in the months of July to September, and hence, it is suitable season for development of VL vectors, because, during the months starts rainy season and the plants, such as Amaranthus spinosa (Amaranthaccae), Musa sapientum, and Croton Sparciflorous are growing well and become very rich sources of breeding habitats, and thus, it attracts $P$. argentipes [20-22], perhaps, bamboo trees (Bambusa Arundinacea) in the pre-domestic areas are most significant factors, because these trees provide shade and consequently fabricate dark and humid weather condition in the neighborhood areas of the house locations, and also creating suitable resting sites for Visceral Leishmaniasis vector population, it has been also supported to the occurring of Kala-azar in endemic prone areas in Sudan, and the distribution of $P$. orientalis vector population has closely been associated with B. aegyptiaca, A. Seyal vegetation land cover [23].

A classical study of mapping of breeding habitats of Kala-azar vector abundance in Bihar, is prone to endemic region of India, shows that vegetation including edible shrubs and plants such as banana, agricultural plantation, orchards etc., with very soft stem are supporting to growth of adult population, and has been providing food and shelter, and hence, it is concluded that the peripheral areas of domestic dwellings with buffering zone of $5 \mathrm{~km}$ radius is most suitable for sandfly vector population [14]. The endemic areas in the affected states of India has rich in tropical moist forest cover and pasture land, covered with shrubs, sparse banana, mango, lychee and palm trees, etc., are the predominant vegetation, which has been supporting for survival and growth of VL vector population in the country. And another 


\section{Visceral Leishmaniasis Cases and Deaths in India}

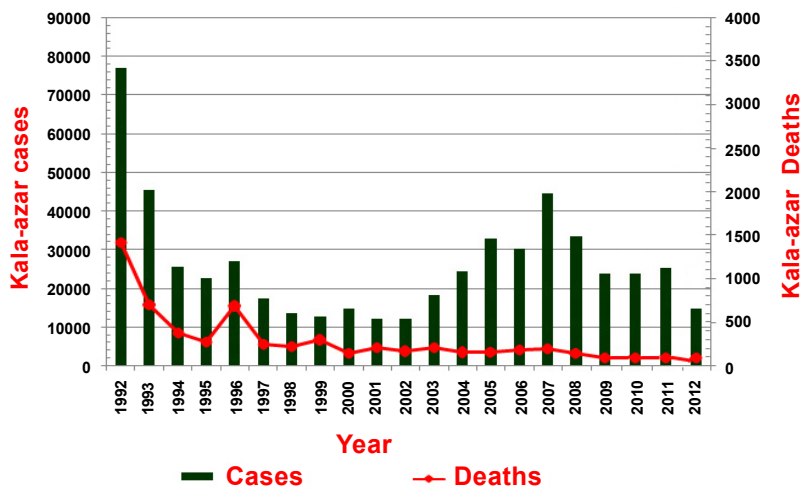

Figure 1: Visceral Leishmaniasis/Kala-azar distribution in the selected states of India (2012).

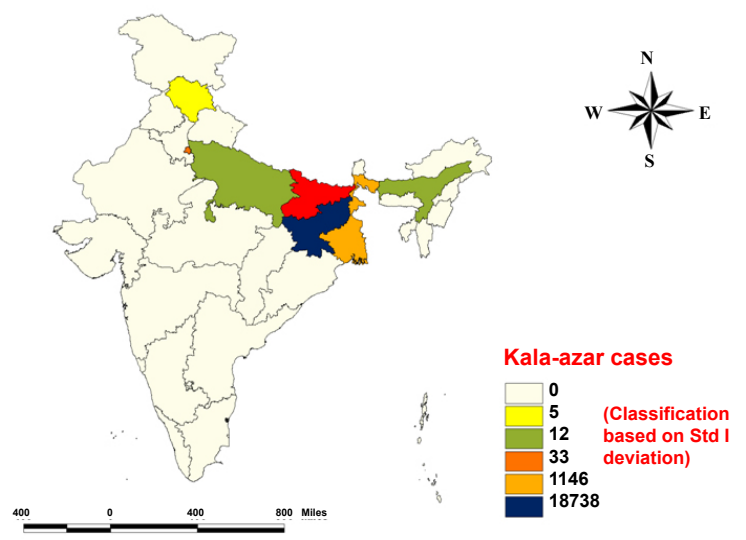

Kala-azar epidemic Transmission in India

Figure 2: Kala-azar cases and deaths occurred in the selected states of India, (1992-2012).

classical study shows that land use/land cover details of map derived from a combination of high spatial resolution satellite data providing the information on vegetation cover and vegetation classification along with surface climate variables have been used for studying and spatial modeling for mapping the abundance of vector population [24], along with soil types, soil moisture and scrub vegetation provides the base line information for stratification of .areas suitable for profusion of $P$. alexandri and P. papatasi, both the species in the desert of Morocco. The geo-statistical model of semivariogram shows that the occurrence of visceral leishmaniasis has been spatially correlated with the vegetation cover, and the NDVI of remote sensing data has spatial autocorrelation with incidence of Visceral Leishmaniasis [25,26], and the spatial analysis of visceral leishmaniasis in northern Brazil, provides the Leishmania parasite abundance and the incidence of disease rate has been varied with level of vegetation cover in the neighborhoods, and hence, to identify proximity to forests and pastures as the major risk factors to a human and wildlife, rather than the peripheral areas [27].

\section{Vegetation indices and visceral leishmaniasis}

The NDVI of remote sensing data, have been predominantly used to studying and mapping the vector borne disease transmission.
Vegetation indices are the reflectance of vegetation in the red and near-infrared wavelengths of multispectral camera of remote sensing satellites. The NDVI has the inherent quality of data pertaining to not only the vegetation cover, but also the landscape environmental variables of soil types, soil depth, soil moisture, soil colour, soil water holding capacity, soil texture, soil pattern, soil moisture regime, slope and elevation of the terrain [28-32]. The spatial predictive model for mapping of vector abundance, using NDVI of remote sensing data and the climate variables, has been found spatially good agreement with statistically significant, says [33,34]. The NDVI value of $<0.2$ indicates less photosynthetically active cover types, $>0.2$ indicates active photosynthetic vegetative cover [35]; suggested as no risk or insignificant and comparatively, as risk areas for Kala-azar endemicity, respectively, says Connor et al., 1995. The different environments, seasons and periods of remotely sensed images have been used for spatial-temporal/time series analysis of disease epidemics and the endemic situation in the country, which has been combined with real time field data to contrast a predictive spatial dynamic model for mapping disease transmission risk in the country as well as global scenario of dynamic world.

\section{The vegetation land cover and Kala-azar incidence}

The high incidence of Visceral Leishmaniasis cases in the geographic location and the vicinity has been closely associated with vegetation density, and is favorable for sandfly abundance in the periphery of Teresina, Brazil [36]. The vegetation type and the climatic factors are playing important role in the Kala-azar transmission [37], The mean and minimum value of NDVI derived from multispectral satellite data has been closely associated with Visceral Leishmaniasis

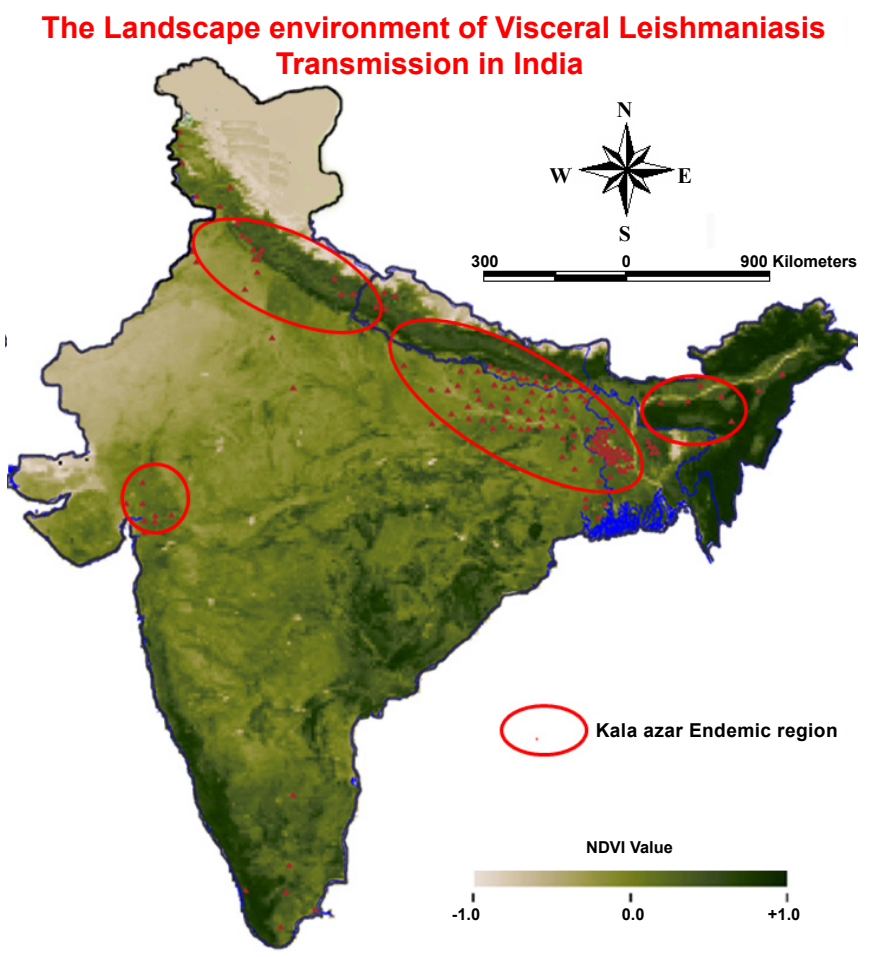

Figure 3: The Visceral Leishmaniasis/Kala-azar endemic data is overlaid on the mean NDVI map of IRS WiFS data of India, the geographical distribution of Kala-azar, is spatially associated with mean composite NDVI value range between $0.08-0.53$, (95\% significance and $5 \%$ error precision with confidence interval, Cl-0.413-0.544), p value $<0.001$. 
transmission [38]. The Kala-azar transmission has been spatially good agreement sparse vegetation cover, than the dense vegetation cover $[12,39]$. The vector abundance is highly with specific vegetation types and breeding habitats, and the vegetation dynamics has been playing important role in the determination of the spatial distribution of the Kala-azar transmission [39]. The NDVI value of the vegetation cover in the eastern Sudan has been highly associated with the sandfly season and should reflect the density of trees, because of the grass land cover in the areas highly seasonal dependant, and flourishing after the start of the rains. The spatial modeling of distribution of Phlebotomus papatasi was developed, using NDVI, was calibrated from NOVA-AVHRR data for the period of 12-years (1982-1994), the results shows that range value of NDVI between $(+) 0.0$ and $(+) 0.06$, along with meteorological data have been spatially determined with vector presence in the Middle East [35].

A higher density of vector abundance has been spatially associated with less dense vegetation zone $[40,41]$. The minimum NDVI in eastern Sudan generally coincides with the sandfly season (Elnaiem et al.,), and the seasonal distribution of $P$. papatasi in South West Asia, has been spatially significant with mean NDVI value of NOAA-AVHRR satellite data, calibrated value between $0.00 \pm 0.06$, of vegetation cover in the grass land of the area is highly seasonal, starts flourishing immediately after the rains [35], and the minimum NDVI value of +0.513 , has the geographic limits of vector presence with caatinga as the predominant vegetation in Brazil [42]. large number of $L u$. longipalpis caught in the patch of the forest, and the marked association of male and females during both dry and wet season, strongly suggested this to be an important breeding sites in the sparse vegetation cover in the reserve forest [43]. In addition to the forest cover, other environmental parameters including soil types, soil moisture, deforestation, and climate determinants are playing important role in the $\mathrm{Lu}$. Longipalpis vector abundance and the distribution of Visceral Leishmaniasis transmision [44,14]. The deforestation for extensive of agricultural land lead to sparse forest cover, provides the perfect breeding grounds for sandfly vector profusion and hence, the risk of human-vector contact and disease transmission [45-47], however, the disease transmission rate was reduced, probably, it could have been related to the regular insecticide spraying in the extensive of agricultural cultivation areas [48].

\section{The Cumulative Effect of Geo-Environmental Variables}

The geographical distribution of Visceral Leishmaniasis otherwise known as Kala-azar in India, has been directly controlled by the specific crop vegetation types, increasing trend of irrigation facilities to the agricultural practices of cultivation areas, amount of rainfall, relative humidity, areas with edible shrubs and plants, alluvial soil type, is dark coloured alkaline in nature with $(\mathrm{pH} 7.2-8.5)$, calcareous with chief inorganic constituents of silicon, iron and aluminium. The predictive climate model shows the best fit with the average altitude (12 m-1900 $\mathrm{m})$, average annual mean temperature $\left(15^{\circ} \mathrm{C}-30^{\circ} \mathrm{C}\right)$, annual rainfall (274 mm-1212 mm), average annual potential evapotranspirations $(1264-1938 \mathrm{~mm})$ and readily available soil moisture $(62-113 \mathrm{~mm})$ for $P$. martini and average altitude $(200 \mathrm{~m}-2200 \mathrm{~m})$, annual rainfall $(\mathrm{I} 80 \mathrm{~mm}-1050 \mathrm{~mm})$, annual mean temperature $\left(16^{\circ} \mathrm{C}-36^{\circ} \mathrm{C}\right)$ and readily available soil moisture $(67-108 \mathrm{~mm})$, alluvial and black cotton soils dark coloured alkaline in nature $(\mathrm{pH} 7.2-8.5)$, calcareous with chief inorganic constituents of silicon, iron and aluminium most suitable for both P.orietalis and Phlebotomus papatasi [15]. This nature of soil enhances its capability of retaining water as well as successful growth and abundance of edible shrubs, plants or agricultural crops.
However, in non-endemic study sites, red and yellow laterite soils, with non-porous granular particles are not only acidic in nature $(\mathrm{pH}$ 5.9-6.1) but are also of less water retaining capacity. The occurrence of Visceral Leishmaniasis/Kala-azar endemic areas has been spatially associated and statistically significant with mean NDVI value of IRS WiFS data of India, with mean composite NDVI value range between $0.08-0.53$, (95\% confidence interval, CI-0.413-0.544), $\mathrm{p}$ value $<0.001$. The geographical limit of risk of Visceral Leishmaniasis transmission is closely associated with soil condition, crop and vegetation in the proximity areas, increase or decrease of temperature $\pm 4^{\circ} \mathrm{C}$, relative humidity $\pm 22.9 \%$ and the mean annual rainfall of $\pm 94 \mathrm{~mm}$ received in the areas, absolutely determine the risk of disease transmission [15]. A geo-spatial analysis of vegetation indices along with surface climate variables have been used for studying and spatial modeling for mapping the abundance of vector population. The study results shows that climate, landscape, and the environments of Kala azar known endemic areas in India, provides the guidelines to demarcate and stratification of areas at risk of Visceral Leishmaniasis transmission or areas has no risk of disease occurrences $[49,50]$.

\section{Conclusion}

Satellite remote sensing of landscape environment and climate data along with geo-referenced Visceral Leishmaniasis disease rate was integrated to the GIS software platform for geo-statistical analysis provides the spatial relationship between the climate (temperature, rainfall, relative humidity, and saturation deficiency), geo-environmental variables (vegetation types, vegetation cover, soil types, soil moistures, soil texture, soil depth, soil chemistry, soil porosity and soil water holding capacity) and the incidence of Kalaazar in India. The hybrid techniques of remote sensing and GIS were used to gaining the better understanding of the spatial variation in the disease incidence and its co-variation with the geo-environmental risk variables, found spatially determined and statistically significant. It is useful to study the vector ecology, mapping vector abundance and the associated risk variables. It was found that climate, vegetation cover, vegetation types and soils, and other environments of peripheral domestic areas are playing important role in controlling the profusion of vector abundance and the prevalence of Visceral Leishmaniasis disease transmission in India.

\section{References}

1. Sharma U, Redhu NS, Mathur P, Singh S (2007) Re-emergence of viscera leishmaniasis in Gujarat, India. J Vect Borne Dis 44: 230-232.

2. Swaminath CS, Supakankunti S (1942) Transmission of Indian Kala-azarto man by the bite of $\mathrm{P}$. argentipes Annadale and Brunetti. The Indian Journal of Medical Research 30: 473-477.

3. World Health Organization (2010) Control of the leishmaniasis. Report of a meeting of the WHO Expert Committee on the control of Leishmaniasis, Geneva, Switzerland.

4. Lysenko A Ja (1971) Distribution of leishmaniasis in the old world. Bull World Health Organ 44: 515-520.

5. World Health Organization (2009) Neglected tropical diseases: hidden successes, emerging opportunities. Geneva, Switzerland.

6. Siddiqui NA, Kumar N, Ranjan A, Pandey K, Das VNR et al. (2010) Awareness about kala-azar disease and related preventive attitudes and practices In a highly endemic rural area of India. Southeast Asian J Trop Med Public Health 41: 1-12.

7. Mondal D, Singh SP, Kumar N (2009) Visceral leishmaniasis elimination programme in India, Bangladesh, and Nepal: reshaping the case finding/case management strategy. PLoS Negl Trop Dis 3: e355.

8. Van Damme W, Leemput LV, Por Ir, Hardeman W, Meessen B (2004) Outof-pocket health expenditure and debt in poor households: evidence from Cambodia. Tropical Medicine and International Health 9: 273-280. 
Citation: Palaniyandi M, Anand PH, Maniyosai R (2014) Climate, Landscape and the Environments of Visceral Leishmaniasis Transmission in India, Using Remote Sensing and GIS. J Geophys Remote Sensing 3: 122. doi:10.4172/2169-0049.1000122

9. Meheus F, Boelaert M, Baltussen R, Sundar S (2006) Costs of patient management of visceral leishmaniasis in Muzaffarpur, Bihar, India. Tropical Medicine and International Health 11: 1715-1724.

10. Thakur CP (2000) Socio-economies of visceral leishmaniasis in Bihar (India). Trans R Soc Trop Med Hyg 94: 156-157.

11. Davey TH, Lightbody WPH (1956) The control of disease in the tropics, London, UK.

12. Bhunia GS, Kesari S, Jeyaram A, Kumar V, Das P (2010) Influence of topography on the endemicity of Kala-azar: a study based on remote sensing and geographical information system. Geospatial Health 4: 155-165.

13. Rossi E, Rinaldi L, Musella V, Veneziano V, Carbone S, et al. (2007) Mapping the main Leishmania phlebotomine vector in the endemic focus of the Mt Vesuvius in southern Italy. Geospatial Health 2: 191-198.

14. Sudhakar S, Srinivas T, Palit A, Kar SK, Battacharya SK (2006) Mapping of risk prone areas of kala-azar (Visceral leishmaniasis) in parts of Bihar state, India: an RS and GIS approach. J Vect Borne Dis 43: 115-122.

15. Gebre-Michael T, Malone JB, Balkewa M, Alia A, Berhe N, et al. (2004) Mapping the potential distribution of Phlebotomus martini and $P$. orientalis (Diptera: Psychodidae), vectors of kala-azar in East Africa by use of geographic information systems. Acta Tropica 90: 73-86.

16. Zeilhofer P, Kummer OP, dos Santos ES, Ribeiro1 ALM, Missawa NA (2008) Spatial modelling of Lutzomyia (Nyssomyia) whitmani s.I.(Antunes \& Coutinho, 1939) (Diptera: Psychodidae: Phlebotominae) habitat suitability in the state of Mato Grosso, Brazil. Mem Inst Oswaldo Cruz Rio de Janeiro 103: 653-660.

17. Jackson RD (1983) Discrimination growth and water stress in wheat by various vegetation indices through clear and turbid atmospheres. Remote Sens Environ 13: 187-208.

18. Bhunia GS, Kumar V, Kumar AJ, Das P, Kesari S (2010) The use of remote sensing in the identification of the eco-environmental factors associated with the risk of human visceral leishmaniasis (kala-azar) on the Gangetic plain, in north-eastern India. Annals of Tropical Medicine \& Parasitology 104: 35-53.

19. Thanyapraneedkul J, Muramatsu K, Daigo M (2009) Improvement accuracy of terrestrial NPP estimation using ADEOS-II/GLI data.

20. Dinesh DS, Dhima RC (1991) Plant source of fructose to sandflies, particularly Phlebotomous argentipes in nature. Journal of communicable Disease 23: 160161.

21. Dhiman RC, Sen AB (1991) Epidemiology of Kala-azar in rural Bihar (India) using village as a component unit of study. Indian J Med Res 93: 155-160.

22. Ranjan A, Sur D, Singh VP, Siddique NA, Manna B, et al. (2005) Risk factors for Indian kala-azar. Am J Trop Med Hyg 73: 74-78.

23. Elnaiem DA, Connor SJ, Thomson MC, Hassan MM, Hassan HK, et al. (1998) Environmental determinants of the distribution of Phlebotomus orientalis in Sudan. Ann Trop Med Parasitol 92: 877-887.

24. Mushinzimana E, Munga S, Minakawa N, Li L, Feng CC, et al. (2006) Use of remote sensing and geographic information system of anopheline mosquito larval habitats in the western Kenya highlands. Malaria Journal 16: 5-13.

25. Werneck GL (2002) The urban spread of Visceral leishmaniasis: clues from spatial analysis. Epidemiology 13: 364-367.

26. Thompson RA, de Oliveria Lima JW, Maguire JH, Braud DH, Scholl DT (2002) Climatic and demographic determinants of American Visceral Leishmaniasis in north-eastern Brazil using remote sensing technology for environmental categorization of rain and region influences on leishmaniasis. Am J Trop Med Hyg 67: 648-655.

27. Nieto P, Malone JB, Bavia ME (2006) Ecological niche modeling for viscera leishmaniasis in the state of Bahia, Brazil, using genetic algorithm for rule-set prediction and growing degree day-water budget analysis. Geospatial Health 1: $115-126$.

28. Wu G, Sun L, Liu Y, Liu H, Sun S, et al. (2002) Impacts of land surface processes on summer climate. Selected Papers of the Fourth Conference on East Asia and Western Pacific Meteorology and Climate, C.-P. Chang et al., Eds. World Scientific, Singapore.

29. Odiit M, Bessell PR, Fevre EM, Robinson T, Kinoti J, et al. (2005) Using remote sensing and geographic information systems to identify villages at high risk for rhodesiense sleeping sickness in Uganda. Transactions of the Royal Society of Tropical Medicine and Hygiene 100: 354-362.
30. Peterson AT, Martinez-Campos C, Nakazawa Y, Martinez-Meyer E (2005) Time-specific ecological niche modeling predicts spatial dynamics of vector insects and human dengue cases. Transactions of the Royal Society of Tropical Medicine and Hygiene 99: 647-655.

31. Raso G (2006) An integrated approach for risk profiling and spatial prediction of Schistosoma mansoni -hookworm co-infection. National Academy of Sciences of the United States of America 103: 6934-6939.

32. Boone RB, Galvin KA, Smith NM, Lynn JS (2000) Generalizing El Nino effects upon Maasai livestock using hierarchical clusters of vegetation patterns. Photogrammetric Engineering \& Remote Sensing 66: 737-744.

33. Rogers DL, Randolph SE, Snow RW, Hay SI (2002) Satellite imagery in the study and forecast of malaria. Nature 415: 710-715.

34. Wood BL, Beck LR, Washino RK, Plachick SM, Sebesta D (1991) Spectral and spatial characterization of the rice field mosquito habitat. Int J Remote Sens 12: $621-626$

35. Cross ER, Newcomb WW, Tucker CJ (1996) Use of weather data and remote sensing to predict the geographic and seasonal distribution of Phlebotomus papatasi in southwest Asia. Am J Trop Med Hyg 54: 530-536.

36. Werneck GL, Costa CHN, Walker AM, David JR, Wand M, Maguire JH (2007) Multilevel modelling of the incidence of visceral leishmaniasis in Teresina, Brazil. Epidemiol. Infect 135: 195-201.

37. Ministério da Saúde (2003) Manual de Vigiláncia e controle de Leishmaniose Visceral: Série A. Normas e Manuais Técnicos, Brazil.

38. Thompson RA, Maguire JH, de Oliveria Lima JW, Scholl DT, Braud DH (2004) Association of remotely sensed environmental indices with visceral leishmaniasis in Brazil. GISVET'04: The applications of GIS and spatial analysis to veterinary science, University of Guelph, Ontario, Canada.

39. Elnaiem DA, Schorscher J, Bendall A, Obsomer V, Osman ME, et al., (2003) Risk mapping of visceral leishmaniasis: the role of local variation in rainfall and altitude on the presence and incidence of kala-azar in eastern sudan. Am J Trop Med Hyg 68: 10-17.

40. Elnaiem DA, Hassan K, Ward RD (1999) Associations of Phlebotomusorientalis and other sandflies with vegetation types in the eastern Sudan focus of kalaazar. Med Vet Entomol 13: 198-203.

41. Dhima RC, Dinesh DS (1992) An experimental study to find out the source of fructose to sandflies. Indian J Parasitol, 16: 159-160.

42. Bavia ME, Carneiro DD, Gurgel Hda C, Madureira FC, Barbosa MG (2005) Remote Sensing and Geographic Information Systems and risk of American visceral leishmaniasis in Bahia, Brazil. Parassitologia 47: 165-169.

43. Lainson R, Rangel EF (2005) Lutzomyialongipalpis and the eco-epidemiology of American visceral leishmaniasis, with particular reference to Brazil -A Review. Mem. Inst. Oswaldo, Cruz Rio de Janeiro 100: 811-827.

44. Desjeux P (2001) The increase risk for leishmaniasis worldwide. Trans Soc Trop Med Hyg 95: 239-241.

45. Rotureau B, Joubert M, Clyti E, Djossou F, Carme B (2006) Leishmaniasis among gold miners, French Guiana. Emerg Infect Dis 12: 1169-1170.

46. Viergever R, Perehudoff K, Esselink M, Sienkiewicz D, Panday BM (2005) Leishmaniasis: A neglected disease. The Dutch secretary of Defense reports to Parliament.

47. Salomon OD, Orellano PW, Lamfrfi M, Scavuzzo M, Dri L, et al. (2006) Phlebotomine spatial distribution associated with a focus of tegumentary leishmaniasis in Las Lomitas, Formosa, Argentina, 2002. Mem. Inst. Oswaldo Cruz, Rio de Janerio 101: 295-299.

48. Mott KE, Nuttall I, Desjeux P, Cattand P (1995) New geographical approaches to control of some parasitic zoonoses. Bulletin of the World Health Organization 73: $247-257$

49. Connor SJ, Thompson MC, Flasse S, Williams JB (1995) The use of low-cost remote sensing and GIS for identifying and monitoring the environmental factors associated with vector-borne disease transmission. GIS for Health and the Environment, International Development and Research Centre (IDRC) Ottawa, Canada.

50. Elnaiem DA, Hassan HK, Ward RD (1997) Phlebotomine sand-flies in a focus of visceral leishmaniasis in a border area of eastern Sudan. Ann Trop Med Parasitol 91: 307-318. 